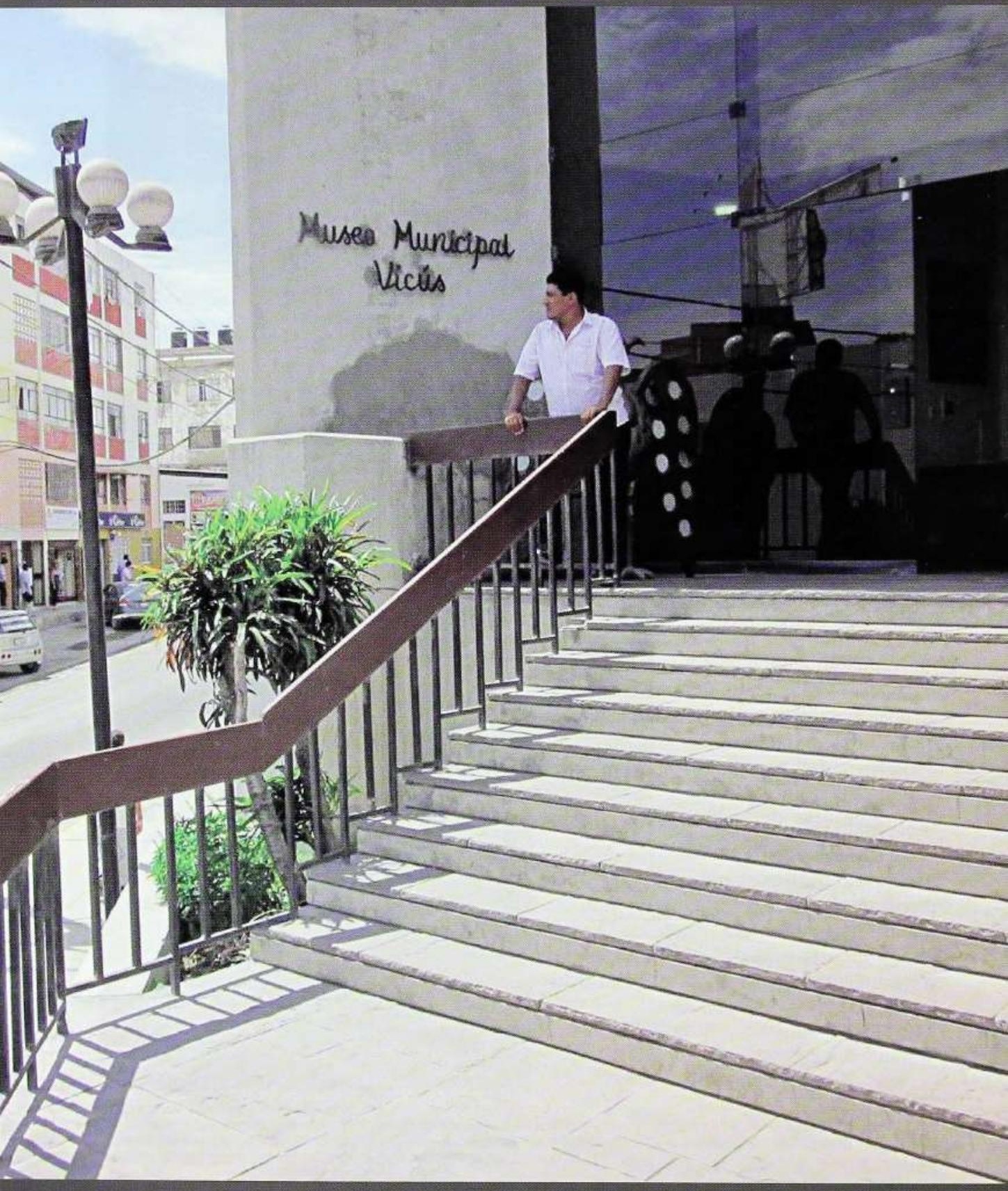




\section{El marketing y su rol en los museos}

Pedro Rodrigo Falcón Sarango / Deyvi Saavedra Ordinola Instituto Confucio - Universidad de Piura

Luego de analizar y corroborar el pobre desempeño de la labor educativa y de marketing en los museos representativos de Piura, en el extremo norte peruano, ponemos atención en los pasos claves para potenciar estos ámbitos de la gestión museal en el corto y mediano plazo, enfatizando la necesidad social y cultural que ello representa para la región, en medio de la búsqueda de su desarrollo integral.

Museo / Piura / Museografía didáctica / Educación museal / Marketing de museos

After analyzing and corroborating the educational and marketing poor performance in representative museums of Piura, at extreme north of Peru, we pay attention to key steps for promoting these areas in museum management in short and long term, emphasizing the cultural and social necessities it represent for the region, among the comprehensive development searching.

Museum / Piura / Educational museography / Museum marketing.

El marketing, aplicado al ámbito cultural, se define como un proceso de gestión de recursos culturales cuyo objetivo es satisfacer las necesidades de diferentes públicos de forma rentable ${ }^{1}$. Esto lo convierte en una herramienta que todo museo debe incorporar en sus planes de desarrollo, buscando la promoción de programas educativos, expositivos y recreativos, estrategias de captación de fondos y ventas, entre otros; que permitan incrementar sus beneficios económicos y, finalmente, lograr la participación activa de sus visitantes y la comunidad.

Se trata de lograr una mirada hacia afuera que permita insertar a sus diferentes grupos sociales inmediatos en el desarrollo museal, lo que implica una aplicación de marketing basado en el análisis profundo de factores externos (perfiles del público, relaciones socioeconómicas, consumo cultural, etc.) e internos (estructura orgánica, objetivos estratégicos, personal, proyectos, etc.), y allí es donde se trasluce una buena estructuración del plan de marketing de la institución.

1 Camero y Garrido, 2004: 64-65. 
En el caso de los museos piuranos observamos que no hay un trabajo enfocado hacia el marketing, demostrándose en la dinámica de visitantes que existe en el Museo Municipal Vicús, la Casa Museo Gran Almirante Grau y el Museo de Sullana².

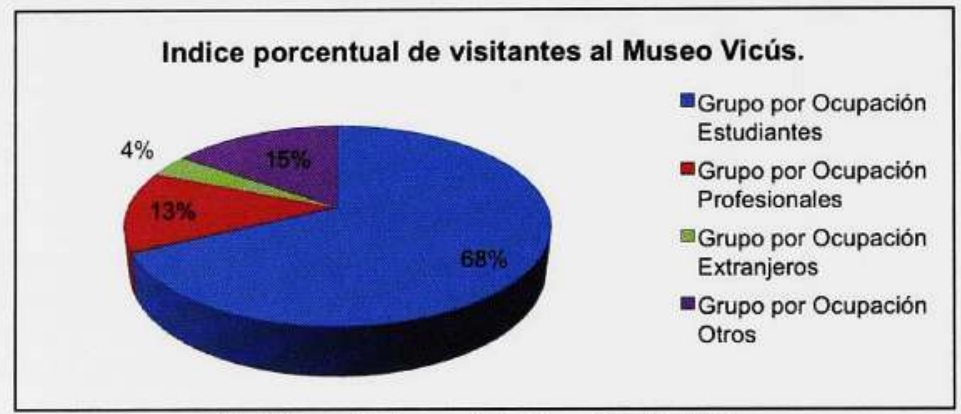

Fig.1: Fuente: Cuadro estadístico Museo Municipal Vicús

Durante 2012, el Museo Vicús fue visitado por un total de 19,250 personas de las cuales el $68 \%$ fue escolar, seguido muy por debajo por visitantes diversos, profesionales y extranjeros. Respecto a la Casa Museo Grau, tuvo un total de 29,376 visitantes, siendo el de mayor índice el público escolar, con un $31 \%$, seguido por particulares, estudiantes, entre otros.

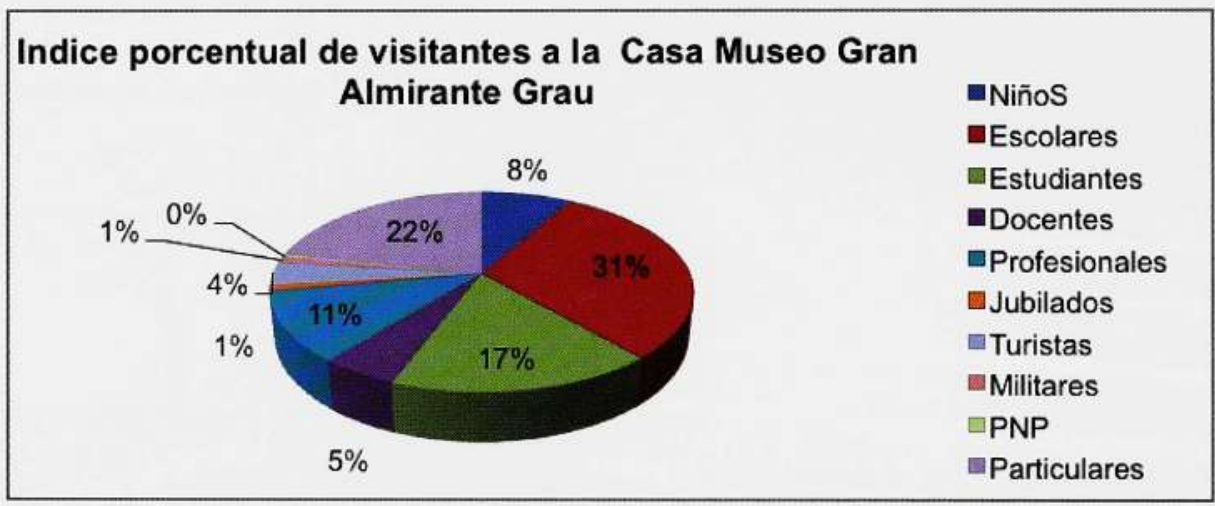

Fig.2: Fuente: Cuadros estadísticos Casa Museo Gran Almirante Grau

Con la data analizada, queda claro que los escolares son el público cautivo de los museos piuranos y las actividades deben dirigirse a fidelizar y ampliar la participación de este segmento. No obstante, es necesario también conocer y captar bajo estrategias eficaces a los demás públicos que de forma pausada pero creciente se vienen involucrando con los espacios museales, sobre todo turistas de la ciudad y los piuranos en edad adulta.

Entre estas estrategias tenemos la implementación de una imagen-marca de cara a lograr un posicionamiento institucional. En ese sentido Cháves considera que una marca en el

2 Es importante resaltar que los tres museos analizados no cuentan con una correcta matriz de segmentación de publicos lo cual representó serios problemas para el análisis estadístico de visitantes. Es por ello que en este apartado solamente se tomará como ejemplo los casos del Museo Municipal Vicús y la Casa Museo Gran Almirante Grau. 
sector cultural cumple una función promocional e identitaria ${ }^{3}$. Esto supone un paso inicial para insertarse de forma diferenciada en el sector cultural regional y ganar una personalidad propia que la comunidad pueda identificar, recordar y relacionar con un producto cultural atractivo y de calidad.

En segundo lugar, buscando incrementar e incentivar la participación activa de los visitantes a nuestros museos se podrían implementar propuestas como: talleres didácticos y recreativos, visitas guiadas por expertos, viajes a lugares patrimoniales, proyectos expositivos que incorporen a diversos agentes y colectivos culturales, programas de visitas corporativas empresariales, visitas nocturnas, talleres de conversación y restauración para aficionados, la implementación de videotecas y bibliotecas especializadas, el alquiler de espacios para eventos, entre otras.

Una última estrategia, capaz de ser implementada a corto plazo en los espacios museales de Piura implica la incorporación de las Tecnologías de la Información (TIC'S) y el marketing digital. En ese sentido, estas instituciones deben desarrollar y mantener una presencia en internet $\mathrm{y}$ redes sociales que permita informar y difundir las actividades del museo, obtener auspicios corporativos, aumentar el índice de visitantes y generar una nueva manera de interacción con los grupos de interés. Como sostiene Piquero García, las nuevas tecnologías han permitido el desarrollo de nuevas formas y productos culturales y artísticos derivando en la aparición y consolidación de nuevos mercados y formas de consumo ${ }^{4}$.

\section{El perfil educador de nuestros espacios museales}

El componente educativo ha sido clave en los museos desde mediados del siglo XX, impulsado por el interés en instruir a las generaciones jóvenes. ${ }^{5}$ Desde instituciones supranacionales como ICOM, hasta agentes y promotores locales, todos han destacado el aspecto pedagógico con el que debe contar el museo $^{6}$.

Sin embargo, no los podemos considerar instituciones educativas en estricto, pues su diversidad de públicos, funciones y servicios no se limita a una intención pedagógica. Estos equipamientos se plantean como un entorno activo para la educación formal e informal, complementando la enseñanza en las instituciones oficiales por un lado, y reforzando actitudes en múltiples etapas de la vida personal, por el otro.

Así, una de las singularidades de la dinámica museística es permitir un aprendizaje libremente escogido, gracias a que cualquier persona auto dirige y orienta visualmente lo que quiere visitar y conocer. No se basa en una guía formativa oficial y lineal para recorrer las salas de exposición, sino en sus propias inquietudes y gustos, pudiendo analizar, reflexionar y disfrutar tanto de temáticas y objetos locales como universales, todo de una forma sintética?.

Esto los convierte en equipamientos culturales muy necesarios en una ciudad pues se constituyen como espacios formativos para la convivencia entre ciudadanos diversos pero tolerantes y libres. Su actuación los puede llevar a ser, como afirma Roser Calaf, en verdaderos "agentes educadores" a lo largo de la vida de las personas.

3 Cháves, 2006: 21-25.

4 Piquero, 2006: 66.

5 Entre los sucesos que originaron este incremento inusitado de museos en las ciudades destaca sin duda los conflictos bélicos y guerras internas. El conocimiento y transmisión de las múltiples consecuencias de estos ha sido clave en las políticas culturales de muchos gobiernos nacionales y regionales, al menos de Europa y buena parte de América.

6 Calaf, 2007: 33.

7 Echarri, 2007: 58. 
En el caso piurano, y a pesar que los profesionales del sector destacan el rol educativo de los museos, ello no se ha traducido en una labor intensa en proyectos educativos y de aprendizaje personal y/o colectivo. Si bien algunos directivos han implementado actividades internas y externas que dotan a sus espacios de presencia y función didáctica, la mayoria han sido efimeras y enfocadas al público escolar primario.

MUSEOS PIURANOS Y SUS ACTIVIDADES DIDACTICAS (De mayor a menor frecuencia de realización)

1. Visita guiada a grupos escolares con previa invitación y coordinación de asistencia

2. Dinámica de descripción y concursos sencillos sobre algunos objetos singulares de las exposiciones permanentes luego del guiado general

3. Invitación a la inauguración de muestras artísticas temporales y eventos artísticos en general a realizarse en las instalaciones del museo

4. Conferencias o coloquios para público especifico escolar/estudiantil o general

Fig.3: Cuadro de las principales acciones que realizan los museos piuranos para el público estudiantil. Elaboración propia.

Este enfoque hacia el público escolar se debe, por un lado, al alto porcentaje de visitas de este segmento (en la Casa Museo Grau, representan el $48 \%$ del total anual de visitas mientras que en el Museo Vicús es el $68^{\circ}$ ). Y por otro, a la propia política de las instituciones tutelares (municipios, principalmente) que enfocan su labor en la educación y recreación de la niñez de la comunidad.

La pobre dinámica educadora en las actividades que producen estos espacios culturales se debe también a una serie de debilidades en su organización y gestión interna. Ello revela la inestabilidad de su labor y el estancamiento que en general han padecido como instituciones durante los últimos años.

\section{El área museal encargada: departamentos educativos}

Los departamentos educativos constituyen un área funcional que diseña e implementa su programación y acción de tipo pedagógica, ya sea desde actividades exclusivas para público escolar, como aquellas dirigidas a otros segmentos. Bajo una metodología definida, el museo genera una serie de "caminos" por los que los estudiantes pueden disfrutar, aprender y actuar en torno a sus contenidos y mensajes, considerando las curriculas y los objetivos de enseñanza docente.

La mayoría de directivos de museos en Piura son docentes vinculados a las Ciencias Sociales, permitiendo un enfoque didáctico en algunas actividades de difusión y visita al espacio. No obstante, se pierde esta intencionalidad y fuerza debido a la pobre articulación con la museografia y dinámicas complementarias como el uso de redes sociales e internet, talleres y dinámica en el recorrido y las salas, etc.

Una de las razones frente a esta situación es la ausencia de un área educativa museal o un encargado principal que diseñe y ejecute efectivamente los programas educativos. La aguda carencia de personal se presenta a su vez como una fuerte debilidad, acompañada de especialización y capacidades para afrontar estas metas pedagógicas.

Sin embargo, estrategias como el voluntariado o la realización de prácticas pre profesionales (o profesionales) para estudiantes y egresados de educación, gestión cultural o comunicación son claves para empezar a mejorar este ámbito museal. 

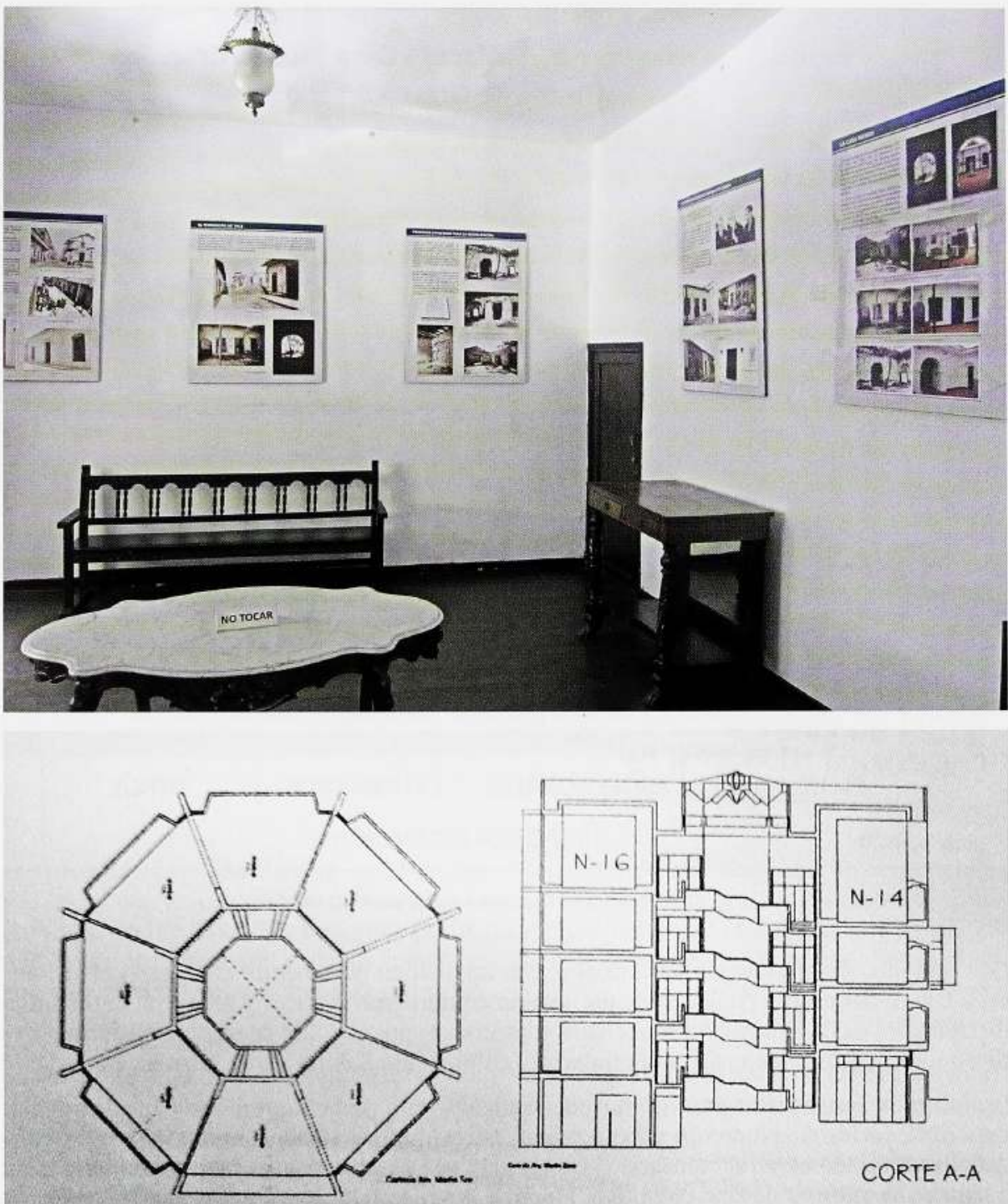

CORTE A-A

Planta Típica del Museo Vicús

Figs. 04 y 05: Muestra de una de las salas de exposición permanente de la Casa Museo Grau (Foto propia), y de la arquitectura del Museo Municipal Vicús (Gráfico de Blanca Alva).

\section{Exposiciones involucradas: museografía didáctica}

Si bien los departamentos educativos suponen la primera área funcional para la puesta en marcha de las estrategias didácticas del museo, también debe integrarse con el área de museografía, de manera que el discurso y montaje expositivo aporte al carácter formativo que se busca. En ese sentido, la museografía didáctica propone la implementación de exposiciones, medios de difusión y estrategias de gestión donde el componente formativo es el articulador de los mensajes y contenidos que los espacios brindan al visitante. 


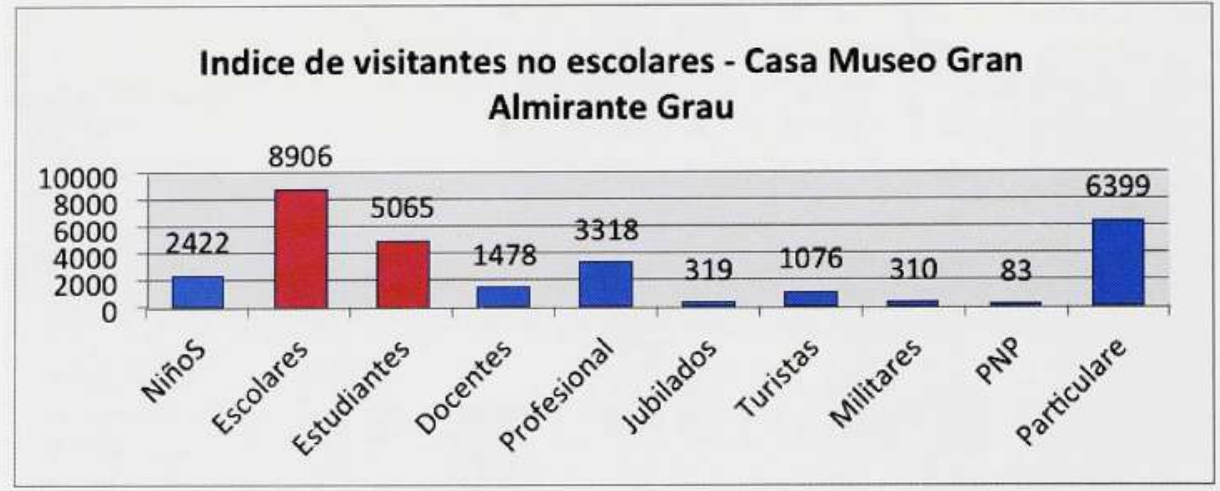

Fig. 06: Fuente: Cuadros Estadísticos Casa Museo Gran Almirante Grau.

\section{Indice de visitantes no escolares - Museo Municipal Vicús.}

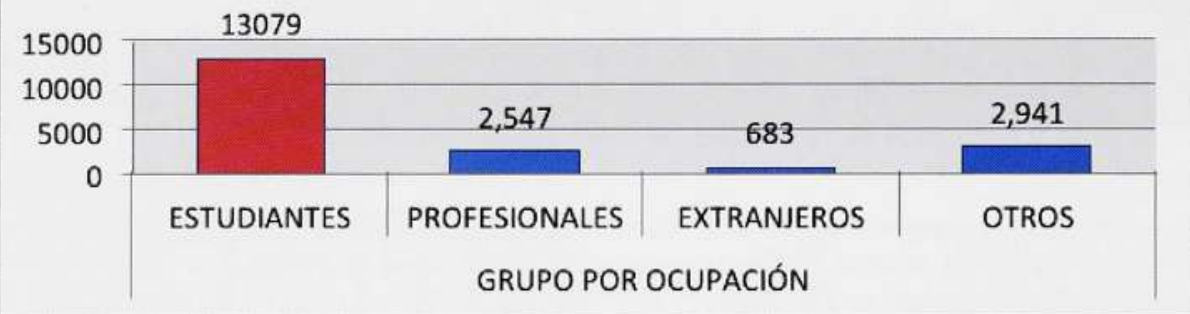

Fig. 07: Fuente: Cuadro Estadistico Museo Municipal Vicús.

Con esta filosofía museística se trata de lograr un diálogo fluido entre el objeto y el visitante, a través del establecimiento de un terreno común entre emisor y receptor, la temática disciplinaria de la exposición museística (discurso expositivo), la presentación formal del diseño e instalación expositiva (iluminación, colores, etc.), entre otros factores claves ${ }^{8}$.

Los objetos constituyen para el museo un agente que posibilita en sus exposiciones la experimentación, exploración y explicación, necesitando por ello que los objetivos educativos partan de ellos, al contrario de la escuela que establece sus objetivos en base a las palabras, sean estos de tipo cognitivo, afectivo, o sensorial ${ }^{9}$.

Así mismo, la interactividad en la museografía didáctica es un componente central que supone la acción tanto del visitante como de la exposición, motivando una retroalimentación hacia el usuario que provoque una interacción adicional. De ahí que en el caso de los centros interactivos surja como una cuarta dimensión ${ }^{10}$.

Basados en estas características, la museografía aplicada en los espacios piuranos muestra muchos vacíos técnicos y metodológicos. Los lineamientos bajo los cuales se han

8 Santacana y Serrat, 2005: 82.

9 SABBATINI, 2004: 200.

10 Ibidem: 142 . 


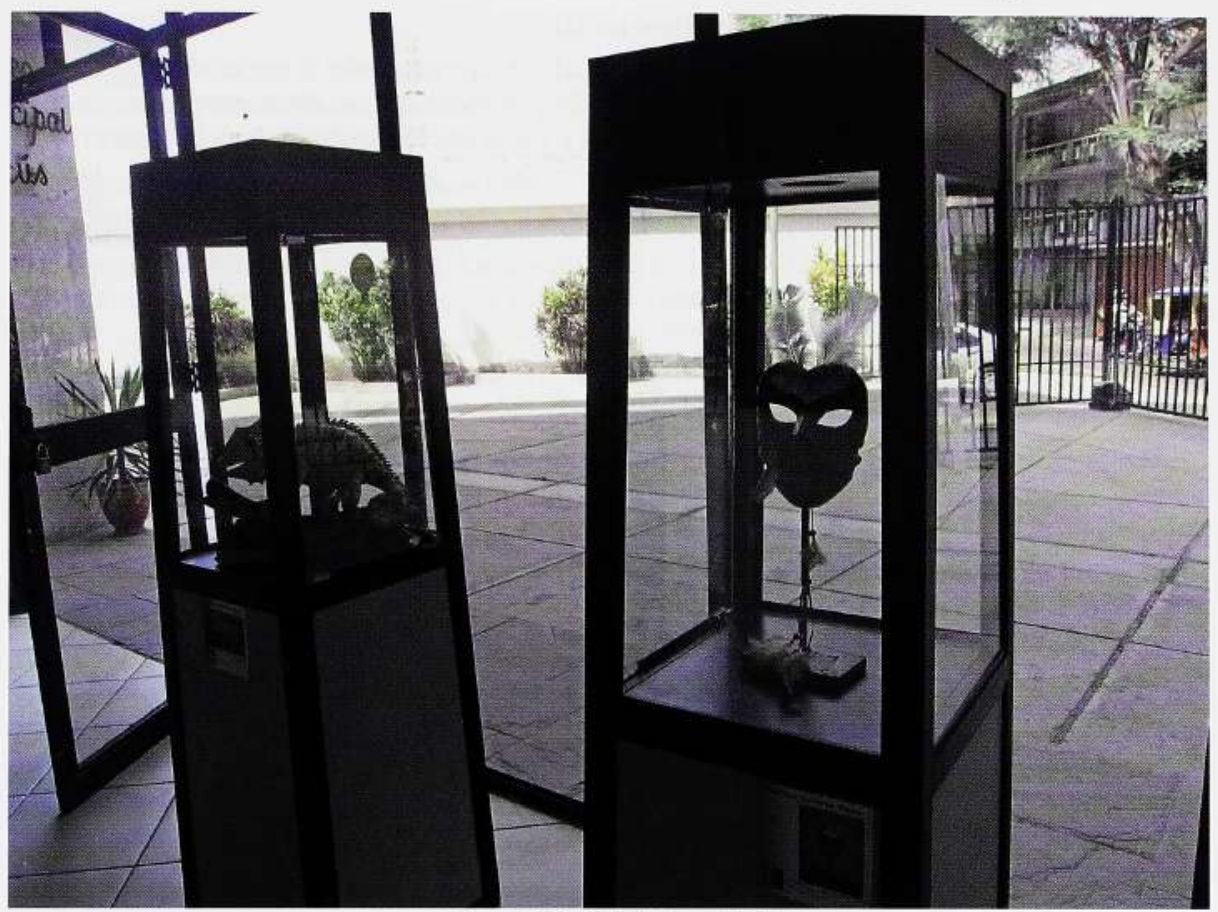

Museo Vicús. Sala de Artes Visuales

estructurado y se difunden las exposiciones resultan de apreciaciones educativas generales y la búsqueda de una instrucción desde el contenido, de forma que los mensajes se trabajan unidireccionalmente y con poca participación del visitante. La iluminación, accesibilidad física, programación y planteamiento conceptual de exposiciones temporales también son muestras operativas de estas carencias.

De la escuela al museo y viceversa

Si desde los equipamientos museísticos no se ha logrado desarrollar efectivas acciones didácticas, su vínculo con las escuelas en la región (incluimos universidades) es muy pobre. Ello a pesar del interés creciente por las visitas guiadas que promueven algunos docentes, pues aunque se dan, no tienen una secuencia que permita fortalecer efectivamente los objetivos que inicialmente se persiguieron.

Llegados aquí, es oportuno reforzar al museo como una estrategia de desarrollo de contenidos y valores que la enseñanza oficial busca concretar en la formación de los estudiantes, siendo uno de los principales el ejercicio de una ciudadanía tolerante y respetuosa en medio de la diversidad cultural.

Con esto, el museo permite que la educación se mantenga atenta a las diferencias y similitudes en las identidades culturales de sus pueblos. La denominada "educación para la diversidad", un nuevo marco teórico de la ciencias educativas, se muestra como un modelo en el que puede adecuarse muy bien la interacción museistica".

11 Santivañez Limas, 2010: 186-189. 


\section{Los museos como espacios de integración social}

La dinámica global de nuestras sociedades actuales ha potenciado la necesidad de que los museos se inserten en la vida comunal influyendo y alimentándose de sus procesos socioeconómicos y culturales, convirtiéndose en ejes y espacios integrales para el encuentro de las personas y grupos de diverso interés.

Trasladando esta consideración a la realidad piurana, notamos que no se ha forjado adecuadamente una estrecha vinculación con la comunidad, siendo la falta de una propuesta de "ocio cultural" atractiva con actividades variadas y propuestas museográficas relevantes su principal razón. Ello queda demostrado en el índice de visitas para el caso de los museos analizados, y que disminuye notablemente tras el segmento escolar tal y como se aprecia en las figuras 06 y 07.

Con la data obtenida, podemos plantear tres binomios cuyas directrices permiten nuestros museos insertarse en la dinámica de desarrollo local. Por un lado, tenemos el museo-empresa en el cual su gestión debe estar al tanto de la oferta y demanda, la competencia de otros equipamientos similares y su rol económico en la sociedad, convirtiéndose en un ente generador de empleos directos e indirectos, nuevos emprendimientos e innovación en la economía de la ciudad.

Por otro lado, se encuentra la relación museo-turismo. En el caso de Piura se podrá aprovechar la dinámica comercial y de negocios para presentarles a los visitantes una oferta de "ocio urbano" que contemple a los museos como un producto cultural prioritario. Ello conlleva a dotar a dichos espacios de servicios y productos claves que hagan atractiva y agradable la visita.

Y por último, debemos señalar el binomio museo-escuela bajo las consideraciones que hemos detallado en apartados arriba.

\section{De necesidad y prioridad pública}

Luego del análisis planteado, podemos considerar que el rol educador de los museos es un reto urgente para regiones como Piura, que afrontan momentos de acelerado cambio y modernización, convirtiéndose en verdaderos espacios clave de conservación y desarrollo cultural, con una fuerte dosis de aprendizaje, recreación y diversión.

El fuerte carácter comercial de nuestra sociedad vuelve urgente también la labor y aplicación de estrategias de marketing, identificando y actuando según segmentos de público, concreción de objetivos de fidelización, posicionamiento, ventas y financiación. Asi, ambos perfiles, el educativo y el de mercadeo en los museos, se muestran como una agenda pendiente en el corto plazo para que estos se conviertan en verdaderos entornos socio culturales activos, y no en "elefantes blancos" o "centros de aburrimiento", que sigue siendo la percepción general más difundida entre la población. 


\section{BIBLIOGRAFÍA}

Alva, Blanca

"Museo Vicús de Piura ¿Proyecto

frustrado?". ILLAPA 03, 2006: 111-120

Calaf Masachs, Roser, Fontal Merillas, Olaia y

Valle Flórez, Rosa Eva

2007 Museos de arte y educación: construir patrimonios desde la diversidad. Asturias: Trea.

Camero Izquierdo, Carmen y Garrido

Samaniego, María José

2004 Marketing del patrimonio cultural. Madrid: Pirámide.

Carbonell, Eduard

2005 "Reflexiones en torno a los museos, hoy". Revista de la Subdirección de Museos Estatales $N^{\circ}$ 1, 2005: 12-21.

Chaves, Norberto

2006 El poder de la marca en la Cultura. En La Comunicacion en la gestion cultural. Grupo Xabide (ed): 21-25. Madrid: Grupo Xabide.

Comisión de Promoción del Perú para la

Exportación y el Turismo

2010 Perfil del Vacacionista Nacional 2011. Lima: Promperú.

Echarri Iribarren, Fernando

2007 Aprendizaje significativo y educación ambiental, aplicaciones didácticas del Museo de Ciencias Naturales de la Universidad de Navarra. España: Fundación Mapfre.

\section{Garcia Eguren, Marta}

Relacion museo-territorio e implementacion didáctica: Museo de la Escuela Rural de Asturias (Tesis Doctoral), Oviedo: Universidad de Oviedo.

Kotler, Philip y Kotler, Neil

2008 Estrategias de marketing para museos. Barcelona: Ariel S.A.

Piquero García, José

2006 Internet, Nuevas tecnologías y Comunicación Cultural. En La

Comunicación en la gestión cultural. Grupo Xabide (ed): 65-70. Madrid: Grupo Xabide.

Puig de la Bellacasa, Borja

2006 Segmentación de públicos y estrategia de comunicación cultural. En $\mathrm{La}$ Comunicacion en la gestion cultural. Grupo Xabide (ed): 39-48. Madrid: Grupo Xabide.

Sabbatini, Marcelo

2004 Museos y centros de ciencia virtuales, complementación y potenciación del aprendizaje de ciencias a través de experimentos virtuales (Tesis Doctoral). Salamanca: Universidad de Salamanca.

Santacana Mestre, Joan y Serrat Antoli, Núria 2005 Museografia didáctica. Barcelona: Ariel.

Santivañez Limas, Vicente

"La educación para la diversidad ¿falacia o realidad?". Cultura 25, 2011: 183-200. 